Article

\title{
Factorial Structure and Psychometric Analysis of the Persian Version of Perceived Competence Scale for Diabetes (PCSD-P)
}

\author{
Habibeh Matin ${ }^{1}$, Haidar Nadrian ${ }^{2} \mathbb{D}$, Parvin Sarbakhsh ${ }^{3}$ and Abdolreza Shaghaghi ${ }^{1,4, *}$ \\ 1 Health Education \& Promotion Department, Faculty of Health, Tabriz University of Medical Sciences, \\ Tabriz, P.C. 5166614711, Iran; habibehmatin@gmail.com \\ 2 Social Determinants of Health Research Center, Tabriz University of Medical Sciences, \\ Tabriz P.C. 5166614711, Iran; haidarnadrian@gmail.com \\ 3 Biostatistics and Epidemiology Department, Faculty of Health, Tabriz University of Medical Sciences, \\ Tabriz P.C. 5166614711, Iran; p.sarbakhsh@gmail.com \\ 4 Medical Education Department, Education Development Centre (EDC), Tabriz University of Medical \\ Sciences, Tabriz P.C. 5166614711, Iran \\ * Correspondence: shaghaghir@tbzmed.ac.ir or ar.shaghaghi@gmail.com; Tel.: +989148416498; \\ Fax: +984133340634
}

Received: 15 March 2019; Accepted: 2 May 2019; Published: 7 May 2019

\begin{abstract}
As a basic psychological need, the level of perceived competence could expedite the achievement of diabetes self-management goals. Because of a lack of a specific data collection tool to measure the level of self-competence among Persian-speaking patients with diabetes, this study was conducted for (1) cross-cultural adaptation and (2) psychometric assessment of the Persian version of the Perceived Competence Scale for Diabetes (PCSD-P). Standard translation/back-translation procedure was carried out to prepare a preliminary draft of the PCSD-P. Content and face validities of the early draft were checked by an expert panel including 15 scholars in the field of health education and promotion as well as nursing education with experience of working and research on diabetes. The final drafted questionnaire was completed by 177 randomly selected patients with type 2 diabetes. On the basis of the collected data, the structural validity of the contrived version was appraised using exploratory and confirmatory factor analysis (EFA, CFA). Cronbach's alpha and intraclass correlation (ICC) coefficients were used to check the scale's reliability and internal consistency. The estimated measures of content validity index $(\mathrm{CVI}=0.95)$ and content validity ratio $(\mathrm{CVR}=0.8)$ were within the acceptable recommended range. The EFA analysis results demonstrated a single factor solution according to the items' loadings for the corresponding component. The model fit indices, that is, root mean square error approximation (RMSEA $=0.000)$, comparative fit index $(\mathrm{CFI}=1)$, Tucker-Lewis index (TLI = 1), incremental fit index (IFI = 1), normed fit index (NFI =0.999), and relative fit index $(\mathrm{RFI}=0.995)$, confirmed the consistency of the hypothesized one-factor solution. The values of the internal consistency and reliability coefficients were also in the vicinity of an acceptable range $(\alpha=0.892$, ICC $=0.886, \mathrm{P}=0.001)$. The study findings revealed good internal validity and applicability of the PCSD-P to measure the degree of self-competence among Persian-speaking type 2 diabetes patients to manage the chronic disease. Owing to unrepresentativeness of the study sample, future cross-cultural tests of PCSD-P are recommended on diverse and broader Persian-speaking populations.
\end{abstract}

Keywords: validation; questionnaire design; self-perception; diabetes mellitus; self-care 


\section{Introduction}

Perceived competence to perform disease management tasks and accomplish allied self-care expectations could play an important role in combating devastating complications of a lifelong persisting disorder such as diabetes. This subjective sense of capability could help patients with diabetes to better manage their disease, that is, to maintain the recommended level of blood glucose and prevent its related complications [1].

Successful management of disease and provision of required cares for patients with diabetes has been one of the major challenges for health systems in recent decades. Given the current number of recognized cases of type 2 diabetes (425 million) [2], it is a challenging task for many health care networks to consolidate limited resources for diabetes care and prevent the related complications [3].

Robust research evidence indicates reciprocal association between the perceived competence for self-management of type 2 diabetes and the measure of blood glucose level [1,4]. Competence is generally reflected on the patients' nutritional behavior, physical activity pattern, stress control, and maintaining type 2 diabetes compatible life style [4,5].

In addition to the motivation and perceived support for individual autonomy [1], the perceived competence is closely related to the concept of self-efficacy [1] and is introduced as one of the important constructs of the self-determination theory (SDT) [6,7]. It was suggested that at least in the context of behavior modification, support of autonomy and motivation could independently lead to the adaption of health boosting behaviors and consequently better health profile [1].

Owing to a wide range of attributes that might affect control of blood glucose level in patients with type 2 diabetes such as severity of the disease, stressful life events, depression, social support, the patients' socioeconomic status and baseline mental status, health care providers (HCPs) should consider the psychological needs of the patients by supporting their autonomy and respecting their viewpoints and dignity while simultaneously providing consistent information about the disease management skills. All these circumspections have favorable effects on the level of perceived competence among type 2 diabetes patients for self-management of their illness, acquisition of healthy behaviors, and maintenance of a decent lifestyle over the disease life course $[1,4,6]$.

Different scales were invented to assess the perceived competence level, including measurement of Children's Perceived Competence (CPCS) [8], perceived competence for patient-centered obesity counseling [9], physical activity [10,11], health related quality of life [12], health behavior and health-related quality of life in patients with cardiovascular disease [13], as well as measurement of competence level for learning medical contents [14]. The Perceived Competence Scale (PCS) is another tool for measurement of perceived competence based on the SDT and has four short parts. The PCS is a consistent instrument in different behavioral domains for the prediction of participants' feelings or compliance with certain commitments [15].

The Perceived Competence Scale for Diabetes (PCSD), which was derived from PCS, had been developed by Williams et al. [16] and could be applicable for assessment of the type 2 diabetes patients' self-competence in managing their disease and regulating their daily activities. The PCSD had been used in various studies on perceived competence of patients with type 2 diabetes and its impact on the disease control and management was dissertated [1,16-21]. The PCSD was also psychometrically tested in different languages $[16,20,22]$. As the PCSD was not validated before for use in the Persian language, and because of a growing number of type 2 diabetes cases in Iran [23-26] and other Persian speaking countries, for example Afghanistan [27] and Tajikistan [28], this study aimed to translate and assess psychometric properties of the PCSD-P for use in Persian-speaking patients with type 2 diabetes.

\section{Materials and Methods}

\subsection{Study Objectives}

The main purpose of this study was to translate and psychometric analysis of the Persian version of the Perceived Competence Scale for Diabetes (PCSD-P). Face and content validity appraisal and 
reliability assessment of the scale were executed according to the standard procedures [29-31], and exploratory factor analysis (EFA) and confirmatory factor analysis (CFA) were performed to test the structural validity of the instrument. Internal consistency and reproducibility of the measure were assessed using the Cronbach $\alpha$ and test-retest intraclass correlation (ICC) coefficients.

\subsection{Study Sample}

The study participants were 177 randomly selected registered patients with type 2 diabetes in the diabetes clinic of the Shahid Madani Hospital in the city of Khoy, northwest of Iran. The sample size was decided in order to comply with the recommended number of cases per item (at least five) to ensure accuracy of the factor analysis process [32,33]. The inclusion criteria included having an active profile in the Diabetes Clinic, over 30 years of age, and native Iranian nationality. The exclusion criteria were emigration to other provinces or countries during the study period, hospitalization due to severe disabling conditions, considerable limiting mental disorders such as Alzheimer's disease or congenital mental retardation, or having a severe limiting disability such as quadriplegia or limiting cardiovascular disease. All these criteria were checked by the research team to guarantee the sampling precision.

\subsection{Measurements}

The original PCSD [16] is a four-item tool that could measure the self-perceived ability of type 2 diabetes patients in controlling and management of several aspects of their disease on a daily basis. The respondents rate their degree of agreement with each item of the questionnaire on a seven-point scale (from 1 representing not at all to 7 representing completely true). The lowest achievable total score of the scale is 4 , which suggests the lowest perceived level of competence, and the highest average score is 28 , which indicates a higher perceived self-care competence $[17,22,34]$.

The standard translation/back-translation procedure was applied $[35,36]$ to translate the original English version of the PCSD into Persian (PCDS-P). Two fluent translators at the first stage translated the English PCSD into Persian and two other proficient translators back translated the Persian version into English. At the latest stage of the process, the prepared back-translated English version of the PCSD was compared with the original version, minor corrections were made, and the final draft was approved by the research team.

Content validity of the PCSD-P was appraised quantitatively and qualitatively by sending the final version of the PCSD-P to a group of experts including 15 specialists in the field of health education and promotion and also nursing staff in the diabetes clinic. On the basis of the experts' feedbacks about relevancy, as well as the clearness and lucidity of the wordings, Lawshe's item-level content validity ratio (CVR) and the instrument level content validity index (CVI) were calculated; all of which were within the acceptable range $(\mathrm{CVI} \geq 0.8$ and $\mathrm{CVR}=0.49)[29,30]$.

To assess internal consistency and reliability of the PCSD-P, Cronbach's alpha and ICC were also measured (ICC was calculated after completing the PCSD-P by 20 patients twice in 20 days interval).

Data collection: The PCSD-P was completed by the trained interviewers for all respondents in a face-to-face interview in a non-directive manner and in one of the clinic's separate and private rooms. The average scale's completion time was 10-15 minutes. During the interview session, the participants were also questioned about their age, sex, marital status, occupation, level of education, permanent living place, nationality, and income.

\subsection{Procedure and Ethical Considerations}

Ethical approval for this study was obtained from the Medical Ethics Board of Trustees in the Tabriz University of Medical Sciences (approval number: IR.TBZMED.REC.1396.192). All of the study participants were provided information about the study objectives, their right to withdraw at any stage without jeopardizing their routine diabetes care or obligation to give reason, and also about confidentiality of the data at the beginning of interview sessions. The written informed consent was obtained from all the attendants or their guardians. 


\subsection{Statistical Analysis}

The study participants' PCSD-P scores distribution was checked for skewness (standard value between -1 and +1 ) and kurtosis (standard value of +1.96 to -1.96 ) and the mean and standard deviations of the scores were estimated [37]. The PCSD-P scores were also examined for ceiling and floor effects, that is, to check whether more than $15 \%$ of the study participants achieved the highest and lowest possible scores, respectively [32].

The scale's estimated Cronbach's alpha reliability index was deemed satisfactory with a value above the threshold level of 0.7 , and the ICC coefficient as an intuitive measure of the scale's test-retest consistency was approved with its value above 0.61 [32].

To check construct validity of the PCSD-P, exploratory and confirmatory factor analyses (EFA and CFA) were performed. Calculation of the Keyser-Meyer-Olkin (KMO) index of sampling adequacy and Bartlett's Test of Sphericity to confirm existence of patterned correlation among the scale's items were carried out in the EFA string using the extraction method of principal axis factoring (PAF) and varimax rotation. Eigenvalues greater than 1 and factor loadings above 0.3 at this stage were considered significant and used for the factor(s) analysis [32]. In the confirmatory factor analysis, the considered acceptable ranges were $0.5-0.8$ for the root mean square error approximation (RMSEA); $0.90-0.95$ for the comparative fit index (CFI); $\chi^{2}<3$ for the value of chi square test; and values above 0.95 for the indices of Bentler-Bonett Normed Fit (NFI), Relative Fit (RFI), Incremental Fit Index (IFI), and Tucker-Lewis Index (TLI) [38,39]. To improve the item-level goodness of fit values and with the modification indices (MI) greater than 7, residual covariance was added to the model [40,41]. The Statistical Package for the Social Sciences (SPSS) (IBM SPSS, Version 20, IBM Corporation, New York, United States) and its added module Analysis of a Moment Structures (AMOS) (IBM SPSS Amos Version 22, Amos Development Corporation, Chicago, United States) were used for statistical analysis.

\section{Results}

\subsection{Sample Characteristics}

Skewness test of the study data revealed a symmetric pattern in the range of a normal distribution $(-0.77)$. The mean total PCSD-P score of the study attendants was 20.79 with the standard deviation of \pm 6.46 . Among the study participants, 3 individuals (1.7\%) had the lowest score (4) and 40 participants $(22.6 \%)$ achieved the highest score (28).

The mean age and standard deviation of the study sample was $57.49 \pm 11.57$ years of which $64.4 \%$ were female and $85.3 \%$ were married. Other attributes of the participants are summarized in Table 1.

Table 1. Socio-demographic characteristics of the study participants to assess psychometric properties of the Perceived Competence Scale for Diabetes in Persian (PCSD-P).

\begin{tabular}{cccc}
\hline Characteristics & & Frequency & Percent \\
\hline \multirow{2}{*}{ Gender } & Male & 63 & 35.6 \\
& Female & 114 & 64.4 \\
\hline \multirow{3}{*}{ Marital Status } & Single & 2 & 1.1 \\
& Married & 151 & 85.3 \\
& Widowed & 22 & 12.4 \\
& Divorced & 2 & 1.1 \\
\hline \multirow{2}{*}{ Occupation } & Employees & 10 & 5.6 \\
& Retired & 26 & 14.7 \\
& Self-employed & 23 & 13 \\
& Housewife & 104 & 58 \\
& Unemployed & 3 & 1.7 \\
\hline
\end{tabular}


Table 1. Cont.

\begin{tabular}{cccc}
\hline Characteristics & & Frequency & Percent \\
\hline \multirow{2}{*}{ Education } & Illiterate & 63 & 35.6 \\
& Primary education & 44 & 24 \\
& Secondary education & 23 & 13 \\
& High school level & 30 & 16.9 \\
& Post-graduate degree & 17 & 9.6 \\
\hline \multirow{2}{*}{ Place of residence } & Urban & 145 & 81.9 \\
& Rural & 32 & 18.1 \\
\hline \multirow{2}{*}{ Income level (RLs: The Iranian national currency) } & $\geq 15$ million & 106 & 59.9 \\
& Without any income & 69 & 39 \\
& & 2 & 1.1 \\
\hline
\end{tabular}

\subsection{Content and Face Validity}

The calculated CVI and CVR based on the experts' feedbacks verified the content and face validity of the PCSD-P. The values of CVR for three questions were higher than 0.8 and above 0.6 for one of the questions. The total CVI score of the scale was 0.95 , which is within the acceptable range [30].

\subsection{Construct Validity}

The EFA preliminary results based on the KMO measure of sampling adequacy $(0.842)$ and value of the $\chi^{2}(748.414, \mathrm{df}=6, \mathrm{P}=0.000)$ verified the suitability of performing the analysis on the study data. A single factor four-item model fit was identified with all the factor loadings above 0.92 , as indicated in Table 2 . The pinpointed factor explained $87.470 \%$ of the total variance within the study data. The model fit was consistent with the empirically derived model in other psychometric studies of the PCSD $[16,22,42]$. The conducted CFA also confirmed the structure of the extracted single factor model in the EFA phase (RMSEA $=0.000, \mathrm{CFI}=1, \mathrm{TLI}=1, \mathrm{IFI}=1, \mathrm{NFI}=0.999 \mathrm{RFI}=0.995)($ Figure 1$)$.

Table 2. Eigenvalues and fit indices in the Psychometric appraisal of the Perceived Competence Scale for Diabetes in Persian (PCSD-P).

\begin{tabular}{cc}
\hline Item & EFA Loadings \\
\hline PCSD1 & 0.927 \\
PCSD2 & 0.953 \\
PCSD3 & 0.934 \\
PCSD4 & 0.927
\end{tabular}

EFA: Exploratory Factor Analyses. Extraction method: principal axis factoring. Rotation method: varimax, values higher than 0.3 were considered for inclusion.

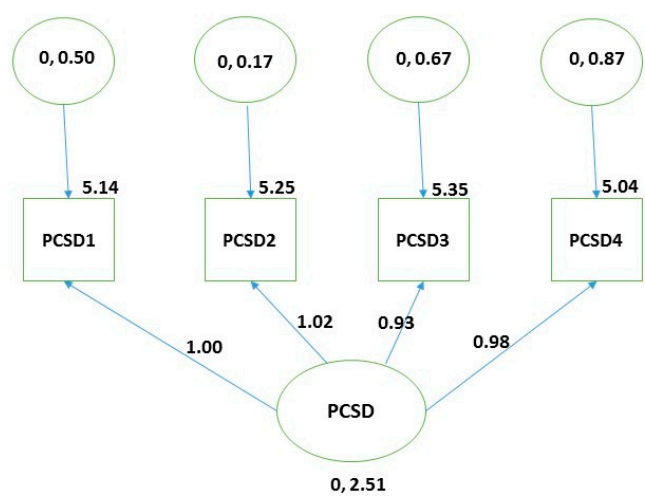

Figure 1. Visual representation of the items' loadings in one component model obtained from confirmatory factor analysis $(n=177)$ in the psychometric appraisal of the Persian Perceived Competence Scale for Diabetes (PCSD-P). 


\subsection{Reliability}

The estimated Cronbach's alpha measure of reliability (0.892) and the test-retest (ICC) measure of the scale's consistency and stability over time $(0.865, \mathrm{P}=0.001)$ were in the acceptable ranges.

\section{Discussion}

The main purpose of this study was psychometric analysis of the Persian version of PCSD (PCSD-P) to be used in research and practice settings for determining the degree of perceived competence for self-care among type 2 diabetes patients. The results revealed a good and acceptable psychometric property for application in Persian speaking patients suffering from type 2 diabetes. On the basis of the results, which were almost consistent with other studies on the psychometric assessment of the PCSD in different languages [16,20,22], this scale can be used as a proper tool for pre-assessment of the patients with type 2 diabetes in clinical or research settings, or post-intervention impact assessments of empowerment intervention targeting type 2 diabetes patients. As with the other translated versions, the PCSD-P demonstrated a robust psychometric performance for use in diabetes related topics and assessment of self-efficacy and sufficiency in overcoming barriers [1,17,18,21].

Content validity: The estimated reliability and internal consistency index of Cronbach's alpha for PCSD-P in this study were almost in the range of calculated measure in other psychometric studies of the PCSD $(\alpha>0.8)[16,20,22,42]$. The approved unidimensionality of the instrument in this study was identical to the results obtained in other studies $[16,22,42]$.

\section{Limitation}

The cross-sectional design of this study prevented the study team from checking whether the degree of perceived competence for self-care among the studied type 2 diabetes patients could lead to a long-term better self-care behavioral profile. The mere reliance on cognitive perception of the patients for self-care and avoiding questions about actual disease oriented self-management behavioral pattern, which could lead in turn to a germane glycemic control algorithm, are the most important drawbacks of the instrument.

At the time of this study implementation, the researchers were not aware of the degree of participants' success in their disease management and this could be a potential confounder that might pose an effect on the study attendants' responses. Patients with a better health profile could have a comparable answer pattern when compared with those who had a worse health profile. This is somehow related to the overall mentality of the patients in the time of responding to questions rather than their actual perceived self-competence.

Despite all these limitations, the consistency of the findings with the results of other studies suggest the applicability of the brief scale as an efficient measure to examine the perceived level of competence for self-care in patients with type 2 diabetes and possibly relate the results to patients' success in better control of glucose level, which is crucial for prevention of the disease's costly and non-reversible complications.

\section{Conclusions}

The current study results provide initial support for the use of the PCSD-P in Persian-speaking type 2 diabetes patients by clinicians and researchers. The findings illustrated the applicability of the PCDS-P to assess patients' perceived competence for self-care and approved the previously reported psychometric properties of the scale in other populations. The results also offered an insight into measurement of a generally neglected attribute in care provision for sufferers of one of the millennium chronic and devastating diseases. The scale could also be applicable as a generic adaptable template for use with other chronic medical conditions. Further research is recommended for cross-cultural validation of the instrument to its application in wider and international scope for comparison purposes. Future studies could address the sensitivity and predictive validity of the scale 
in measurement of perceived competence changes over time and self-care outcome when self-care competency improvement interventions are being taken for overall health promotion purposes.

Author Contributions: Conceptualization, H.M. and A.S.; Data curation, H.M. and A.S.; Formal analysis, H.M., P.S. and A.S.; Funding acquisition, A.S.; Investigation, H.M. and A.S.; Methodology, H.M., H.N., P.S., and A.S.; Project administration, H.M., H.N., and A.S.; Resources, H.M. and A.S.; Software, H.M. and P.S.; Supervision, A.S. and H.N.; Validation, H.M., and A.S.; Visualization, H.M.; Writing-original draft, H.M., H.N., and A.S.; Writing-review \& editing, H.M., H.N., P.S., and A.S.

Funding: This research was funded by the Tabriz University of Medical Sciences, grant number 5-D-476070-96-04-25".

Acknowledgments: The authors of the paper would like to especially appreciate the Dean of the Khoy Faculty of Medical Sciences, Chief Executive Officer (CEO) of the Shahid Madani hospital, the nurse supervisor in the Diabetes Clinic, and all participant for their continued cooperation in this project. The authors also would like to appreciate Dr L.J. Dastjerdi for her kind help and useful comments in successful implementation of the study.

Conflicts of Interest: The authors confirm that no financial or other kind of potential conflicts of interest exist for any of the authors of this study.

\section{References}

1. Mohn, J.; Graue, M.; Assmus, J.; Zoffmann, V.; Thordarson, H.B.; Peyrot, M.; Rokne, B. Self-reported diabetes self-management competence and support from healthcare providers in achieving autonomy are negatively associated with diabetes distress in adults with Type 1 diabetes. Diabet. Med. 2015, 32, 1513-1519. [CrossRef]

2. Global Report on Diabetes. Available online: http://www.who.int/diabetes/global-report/en/ (accessed on 12 March 2019).

3. Diabetes Programme. Available online: https://www.who.int/diabetes/goal/en/ (accessed on 12 March 2019).

4. Koponen, A.M.; Simonsen, N.; Laamanen, R.; Suominen, S. Health-care climate, perceived self-care competence, and glycemic control among patients with type 2 diabetes in primary care. Health Psychol. Open 2015, 2. [CrossRef] [PubMed]

5. Cunningham, A.T.; Crittendon, D.R.; White, N.; Mills, G.D.; Diaz, V.; LaNoue, M.D. The effect of diabetes self-management education on $\mathrm{HbA} 1 \mathrm{c}$ and quality of life in African-Americans: A systematic review and meta-analysis. BMC Health Serv. Res. 2018, 16, 367. [CrossRef]

6. selfdeterminationtheory.org. Available online: http://selfdeterminationtheory.org/ (accessed on 12 March 2019).

7. Deci, E.L.; Ryan, R.M. Intrinsic Motivation and Self-Determination in Human Behavior; Plenum: New York, NY, USA, 1985. Available online: https:/www.springer.com/gp/book/9780306420221 (accessed on 12 March 2019).

8. Nagai, Y.; Nomura, K.; Nagata, M.; Ohgi, S.; Iwasa, M. Children's Perceived Competence Scale: Reference values in Japan. J. Child Health Care 2015, 19, 532-541. [CrossRef] [PubMed]

9. Burton, A.M.; Brezausek, C.M.; Hendricks, P.S.; Agne, A.A.; Hankins, S.L.; Cherrington, A.L. Development of a Tool to Assess Resident Physicians' Perceived Competence for Patient-centered Obesity Counseling. J. Educ. Train. Stud. 2015, 3, 73-79. [CrossRef]

10. Trew, K.; Scully, D.; Kremer, J.; Oghle, S. Sport, Leisure and Perceived Self-Competence among Male and Female Adolescents. Eur. Phys. Educ. Rev. 1999, 5, 53-74. [CrossRef]

11. Sollerhed, A.C.; Apitzsch, E.; Råstam, L.; Ejlertsson, G. Factors associated with young children's self-perceived physical competence and self-reported physical activity. Health Educ. Res. 2008, 23, 125-136. [CrossRef]

12. Empelen, R.V.; Jennekens-schinkel, A.; Rijen, P.C.V.; Helders, P.J.M.; Nieuwenhuisen, O.V. Health-related quality of life and self-perceived competence of children assessed before and up to two years after Epilepsy surgery. Epilepsia 2005, 46, 258-271. [CrossRef]

13. Bachmann, J.M.; Goggins, K.M.; Nwosu, S.K.; Schildcrout, J.S.; Kripalani, S.; Wallston, K.A. Perceived Health Competence Predicts Health Behavior and Health-Related Quality of Life in Patients with Cardiovascular Disease. Patient Educ. Couns. 2016, 99, 2071-2079. [CrossRef] [PubMed]

14. Carney, P.A.; Palmer, R.T.; Miller, M.F.; Thayer, E.K.; Estroff, S.E.; Litzelman, D.K.; Biagioli, F.E.; Teal, C.R.; Lambros, A.; Hatt, W.J.; et al. Tools to Assess Behavioral and Social Science Competencies in Medical Education: A Systematic Review. Acad. Med. 2016, 91, 730-742. [CrossRef] 
15. Instruments, Perceived Competence Scale (PCS). Available online: http://stelar.edc.org/instruments/perceivedcompetence-scale-pcs/ (accessed on 12 March 2019).

16. Williams, G.C.; Freedman, Z.R.; Deci, E.L. Supporting Autonomy to Motivate Patients with Diabetes for Glucose Control. Diabetes Care 1998, 21, 1644-1651. [CrossRef]

17. Juul, L.; Maindal, H.T.; Zoffmann, V.; Frydenberg, M.; Sandbaek, A. Effectiveness of a Training Course for General Practice Nurses in Motivation Support in Type 2 Diabetes Care: A Cluster-Randomised Trial. PLOS ONE 2014, 9, e96683. [CrossRef]

18. Koponen, A.; Simonsen, N.; Suominen, S. Health care climate and outcomes of care among patients with type 2 diabetes in Finland in 2011. J. Public Health 2014, 24, 366. [CrossRef]

19. Kane, E.P.; Collinsworth, A.W.; Schmidt, K.L.; Brown, R.M.; Snead, C.A.; Barnes, S.A.; Fleming, N.S.; Walton, J.W. Improving diabetes care and outcomes with community health workers. Fam. Pract. 2016, 33, 523-528. [CrossRef] [PubMed]

20. Williams, G.C.; Deci, E.L. Internalization of Biopsychososial Values by Medical Student: A Test of Self Determination Theory. J. Personal. Soc. Psychol. 1996, 70, 767-779. [CrossRef]

21. Rosenbek Minet, L.K.; Wagner, L.; Lønvig, E.M.; Hjelmborg, J.; Henriksen, J.E. The effect of motivational interviewing on glycaemic control and perceived competence of diabetes self-management in patients with type 1 and type 2 diabetes mellitus after attending a group education programme: A randomised controlled trial. Diabetologia 2011, 54, 1620-1629. [CrossRef]

22. Williams, G.C.; McGregor, H.A.; King, D.; Nelson, C.C.; Glasgow, R.E. Variation in perceived competence, glycemic control, and patient satisfaction: Relationship to autonomy support from physicians. Patient Educ. Couns. 2005, 57, 39-45. [CrossRef]

23. Esteghamati, A.; Larijani, B.; Aghajani, M.H.; Ghaemi, F.; Kermanchi, J.; Shahrami, A.; Saadat, M.; Esfahani, E.N.; Ganji, M.; Noshad, S.; et al. Diabetes in Iran: Prospective Analysis from First Nationwide Diabetes Report of National Program for Prevention and Control of Diabetes (NPPCD-2016). Sci. Rep. 2017, 7, 13461. [CrossRef]

24. Islamic Republic of Iran. World Health Organization-Diabetes Country Profiles. 2016. Available online: https://www.who.int/diabetes/country-profiles/irn_en.pdf (accessed on 12 March 2019).

25. Nasli-Esfahani, E.; Farzadfar, F.; Kouhnavard, M.; Ghodssi-Ghassemabadi, R.; Khajavi, A.; Peimani, M.; Razmandeh, R.; Vala, M.; Shafiee, G.; Rambod, C.; et al. Iran Diabetes Research Roadmap (IDRR) Study: A Preliminary Study on Diabetes Research in the World and Iran. J. Diabetes Metab. Disord. 2017, 16, 9. [CrossRef]

26. Peimani, M.; Abrishami, Z.; Nasli Esfahani, E.; Bandarian, F.; Ghodsi, M.; Larijani, B. Iran Diabetes Research Roadmap (IDRR) Study: Analysis of Diabetes Comorbidity Studies in Iran: A Review Article. Iran J. Public Health 2017, 46, 39-46.

27. Islam Saeed, K.M. Diabetes Mellitus among Adults in Herat, Afghanistan: A Cross-Sectional Study. Cent. Asian J. Glob. Health 2017, 6, 271. [CrossRef] [PubMed]

28. Tajikistan. World Health Organization—Diabetes Country Profiles. 2016. Available online: https://www. who.int/diabetes/country-profiles/tjk_en.pdf (accessed on 12 March 2019).

29. Lawshe, C.H. A Quantitative Approach to Content Validity. Pers. Psychol. 2006, 28, 563-575. [CrossRef]

30. Polit, D.F.; Beck, C.T. The Content Validity Index: Are You Sure You Know What's Being Reported? Critique and Recommendations. Res. Nurs. Health 2006, 29, 489-497. [CrossRef]

31. Shultz, K.S.; Whitney, D.J.; Zickar, M.J. Measurement Theory in Action: Case Studies and Exercises, 2nd ed.; Routledge: New York, NY, USA, 2014; pp. 83-87. Available online: https://books.google.com/books?id= GjEkAgAAQBAJ\&pg=PA87\&lpg=PA87\&dq=Formalizing+content+validity (accessed on 10 April 2019).

32. Mirfeizi, M.; Asghari Jafarabadi, M.; Mehdizadeh Toorzani, Z.; Mohammadi, S.M.; Dehghan Azad, M.; Vizheh Mohammadi, A.; Teimori, Z. Feasibility, reliability and validity of the Iranian version of the Diabetes Quality of Life Brief Clinical Inventory (IDQOL-BCI). Diabetes Res. Clin. Pract. 2012, 96, 237-247. [CrossRef] [PubMed]

33. Yong, A.G.; Pearce, S. A Beginner's Guide to Factor Analysis: Focusing on Exploratory Factor Analysis. Tutor. Quant. Methods Psychol. 2013, 9, 79-94. [CrossRef]

34. Mohn, J.; Graue, M.; Assmus, J.; Zoffmann, V.; Thordarson, H.; Peyrot, M.; Rokne, B. The effect of guided self-determination on self-management in persons with type 1 diabetes mellitus and $\mathrm{HbA} 1 \mathrm{c} \geq 64 \mathrm{mmol} / \mathrm{mol}$ : A group-based randomised controlled trial. BMJ Open 2017, 7, e013295. [CrossRef] [PubMed] 
35. Nemeth, C.P. Human Factors Methods for Design: Making Systems Human-Centered; CRC Press LLC: Boca Raton, FL, USA, 2004.

36. Process of Translation and Adaptation of Instruments. Available online: https://www.who.int/substance abuse/research_tools/translation/en/ (accessed on 13 March 2019).

37. Chehreay, A.; Haghdoust, A.A.; Freshteneghad, S.M.; Baiat, A. Statistical Analysis in Medical Science Researches Using SPSS Software, 1st ed.; Pezhvak e Elm e AriaL: Tehran, Iran, 2010.

38. Schreiber, J.B.; Stage, F.K.; King, J.; Nora, A.; Barlow, E.A. Reporting Structural Equation Modeling and Confirmatory Factor Analysis Results: A Review. J. Educ. Res. 2006, 99, 323-337. [CrossRef]

39. Frielink, N.; Schuengel, C.; Embregts, P.J.C.M. Autonomy support in people with mild-to-borderline intellectual disability: Testing the Health Care Climate Questionnaire-Intellectual Disability. J. Appl. Res. Intellect. Disabil. 2018, 31, 159-163. [CrossRef]

40. Structural Equation Modeling Using AMOS an Introduction. Available online: https://stat.utexas.edu/ images/SSC/Site/AMOS_Tutorial.pdf (accessed on 12 March 2019).

41. Schinka, J.A.; Velicer, W.F.; Weiner, I.B. Handbook of Psychology, Research Methods in Psychology, 2nd ed.; John Wiley \& Sons, Inc.: Hoboken, NJ, USA, 2003; p. 92. Available online: https://books.google.com/books?id= MnOyiy5dtSsC\&pg=PA92\&lpg=PA92\&dq=modification+indices (accessed on 12 March 2019).

42. Williams, G.C.; McGregor, H.A.; Freedman, Z.R.; Zeldman, A.; Deci, E.L. Testing a Self-Determination Theory Process Model for Promoting Glycemic Control through Diabetes Self-Management. Health Psychol. 2004, 23, 58-66. [CrossRef]

(C) 2019 by the authors. Licensee MDPI, Basel, Switzerland. This article is an open access article distributed under the terms and conditions of the Creative Commons Attribution (CC BY) license (http://creativecommons.org/licenses/by/4.0/). 